\title{
¿Centros o cuerpos de delegados? Las luchas estudiantiles de los años setenta frente al debate acerca de las formas organizativas. El caso de la UBA
}

\section{Student centers or bodies o delegates? The student struggles of the seventy years against the debate about the organizational forms. The case of the UBA}

\author{
Juan Sebastián Califa \\ Instituto de Historia Argentina y Americana "Dr Emilio Ravignani", \\ Consejo Nacional de Investigaciones Científicas y Técnicas, \\ Facultad de Filosofía y Letras, \\ Facultad de Ciencias Sociales, \\ Universidad de Buenos Aires (Argentina) \\ jscalifa@hotmail.com
}

\begin{abstract}
Resumen
En este trabajo se dará cuenta de las pujas generadas a comienzos de los años setenta en el movimiento estudiantil argentino en lo concerniente a los principios organizativos más eficaces para derrotar a la dictadura imperante. Mientras que el reformismo bregaba por reconstruir los centros de estudiantes, otras organizaciones de izquierda y en menor medida peronistas se orientaban a fortalecer los cuerpos de delegados por curso. Los avatares de esta competencia, con sus ganadores y perdedores, permite adentrarse en un período clave de la universidad argentina, revisitando así el debate acerca de la vigencia del reformismo como identidad programática entre sus capas más jóvenes. Este artículo, se adentrará en lo acaecido en la Universidad de Buenos Aires (UBA), acudiendo a fuentes y bibliografía variada.
\end{abstract}

Palabras claves

centros de estudiantes; cuerpos de delegados; los setenta; reforma; Universidad de Buenos Aires

\begin{abstract}
In this paper, we will see the bids generated in the early seventies in the Argentine student movement regarding the most effective organizing principles to defeat the ruling dictatorship. While reformism struggled to rebuild student centers, other organizations of the left and, to a lesser extent, Peronists aimed to strengthen the bodies of delegates per course. The ups and downs of this competition, with its winners and losers, allows us to enter a key period of the Argentine university, revisiting the debate about the validity of reformism as a programmatic identity among its younger layers. This article will delve into what happened at the University of Buenos Aires (UBA), going to sources and bibliography varied.
\end{abstract}

Esta obra está sujeta a la Licencia Reconocimiento-NoComercial-CompartirIgual 4.0 Internacional de Creative Commons. http://creativecommons.org/licenses/by-nc-sa/4.0/ 


\section{¿Centros o cuerpos de delegados? Las luchas estudiantiles de los años setenta frente al debate acerca de las formas organizativas. El caso de la UBA}

\section{Keywords}

student centers; bodies of delegates; the seventies; reform; University of Buenos Aires

\section{La "Revolución Argentina" y su ataque al movimiento estudiantil}

La dictadura que asumió tras el golpe de Estado del 28 de junio de 1966, la autodenominada "Revolución Argentina", se enfrentó férreamente al movimiento estudiantil, y en especial a sus organizaciones reformistas mayoritarias, al considerarlo un canal de ascenso del comunismo vernáculo. ${ }^{1}$ En una atmósfera de "Guerra Fría" marcada por la polaridad social entre los bloques liderados por el comunismo soviético y el capitalismo estadounidense, lo sucedido en la educación superior disparaba alertas en las clases dominantes. En ese sentido debe interpretarse la intervención de las universidades públicas del 29 de julio que clausuró el cogobierno y la autonomía, esto es, los pilares reformistas sobre los que se desenvolvían los más de doscientos mil estudiantes que pululaban por sus aulas.

La intervención tuvo su epicentro en en la Facultad de Ciencias Exactas y Naturales de la Universidad de Buenos Aires (UBA), durante la llamada Noche de los Bastones Largos. En esa jornada fueron detenidos alrededor de 150 estudiantes y docentes, se efectuaron simulacros de fusilamiento y la policía golpeó con bastones a numerosos universitarios. ${ }^{2}$ Una vez concretada, más de mil docentes resolvieron renunciar a sus cargos en esta universidad; cuando se resistieron fueron expulsados sin más. ${ }^{3}$ De este modo, se desmantelaron los equipos de investigación que animaban una descollante vida científica. En ese trance, bajo una sostenida represión, la oposición estudiantil resultó derrotada en las calles y las aulas. Los centros de estudiantes, forma organizativa que habían antecedido a la Reforma Universitaria de 1918, pero que tras su estela se habían potenciado notablemente, se vieron severamente afectados. ${ }^{4}$ En muchas ocasiones, como sucedió en las facultades de Ingeniería o Ciencias Económicas, estos fueron clausurados raudamente. Destruidos sus bienes, desterrados sus locales y perseguidos sus militantes, los centros apenas pudieron preservar un mínimo de actividad gremial y política.

Durante 1968, año en que la lucha estudiantil sobresalió en todo el globo, el movimiento estudiantil argentino comenzó a recuperar terreno perdido. Al año

\footnotetext{
${ }_{1}$ Pablo Buchbinder. Historia de las universidades argentinas. Buenos Aires, Sudamericana, 2005, p. 118. Este trabajo resulta muy adecuado en tanto síntesis crítica de los conceptos vertidos en este apartado.

2 Beatriz Baña, Carlos Borches, Raúl Carnota y Eduardo Díaz de Guijarro. Historia de la Facultad de Ciencias Exactas y Naturales. Universidad de Buenos Aires, 2015. p. 234 y ss. Un análisis más general puede verse en Sergio Morero. La noche de los bastones largos: 30 años después. Buenos Aires, Página $12,1996$.

${ }^{3}$ La cifra de renunciantes es proporcionada por la "Junta Coordinadora de Profesores, Graduados y Estudiantes de la Universidad de Buenos Aires”, Boletín № 3, p. 1 (CEDINCI). Recientemente, el Consejo Superior de la UBA, en su sesión del 13 de julio de 2016 y en una resolución ad referéndum posterior que incorporó nuevos nombres, identificó 1.106 trabajadores (la mayoría docentes) entre renunciantes, cesanteados y expulsados. La Facultad de Ciencias Exactas y Naturales con 328 personas, Arquitectura con 253 y Filosofía y Letras con 182, resultaron las unidades académicas más afectadas. Véase La Noche de los Bastones Largos: cincuenta años 1966-2016. Buenos Aires, Eudeba, 2016, p. 89 y ss.

4 Juan Sebastián Califa. "A los golpes con el golpe". Conflicto Social. Revista del Programa de Investigaciones sobre Conflicto Social, № 13. Buenos Aires, 2015, pp. 89-115.
} 
siguiente la conflictividad universitaria siguió creciendo, como lo pusieron de manifiesto los "azos" que los estudiantes protagonizaron en distintas ciudades del país junto a los obreros. ${ }^{5}$ Entrada la nueva década, la correlación de fuerzas con la dictadura se revirtió definitivamente, pasando los universitarios a la ofensiva. En ese contexto, el debate acerca de las formas organizativas más pertinentes para enfrentar al gobierno se potenció ¿Se debía retornar a los centros de estudiantes o era necesario prodigar nuevas organizaciones? Esta disyuntiva no se resolvería en el terreno teórico, sino mediante la confrontación política.

En las páginas que siguen se reconstruirá el accionar de tales cuerpos de delegados, teniendo en cuenta cómo surgieron y actuaron y tratando de responder las razones de su declive. Nuestro encuadre metodológico privilegiará la observación de los enfrentamientos sociales en que se involucraron estas entidades para dar cuenta de su derrotero. ${ }^{6}$

\section{El relanzamiento de los centros de estudiantes}

Los centros de estudiantes constituían gremios estudiantiles que, si bien antecedieron a la Reforma de 1918, se potenciaron con el sujeto que construyó esta gesta.7 Quienes se identificaban con esta lucha, los reformistas, propiciaron la organización del estudiantado en torno a estas entidades como un modo de vehiculizar, y sobre todo moldear, las demandas del claustro más joven. Sin embargo, más allá de la defensa corporativa de sus adherentes, y de las tareas gremiales que abarcaron, los centros también nadaron las turbias aguas de la lucha política. Su momento más álgido se dio tras el golpe de Estado de 1943 y, peor aún para estas, con los años peronistas, que pusieron a estos organismos estudiantiles al borde de la ilegalidad, cuando no los proscribieron y reemplazaron por entidades adictas a los funcionarios universitarios de turno. ${ }^{8}$ Tras el nuevo golpe de Estado de 1955, el reformismo relanzó estas instituciones. La legalidad que este actor recobró le permitió multiplicar sus adherentes, más teniendo en cuenta que la mayoría de los centros en la UBA estipulaban una cuota de afiliación para integrar sus filas.

Las tensiones políticas crecientes de los años sesenta llevaron a estas entidades a ocupar cada vez más un rol abiertamente político. Los comunistas, al frente de su dirección, entretejieron un cuidadoso equilibrio entre su acción política y gremial, con el objetivo de que la segunda potenciara a la primera. El peligro que suponía su crecimiento político para el orden burgués fue entrevisto por la dictadura que, tras el golpe de Estado, no tardó en atacar a los centros y, con ello, cualquier

\footnotetext{
${ }^{5}$ Véase Mariano Millán. Entre la Universidad y la política. Los movimientos estudiantiles de Corrientes y, Rosario, Córdoba y Tucumán durante la "Revolución Argentina" (1966-1973). Tesis de Doctorado. Buenos Aires, Facultad de Ciencias Sociales de la Universidad de Buenos Aires, 2013.

${ }^{6}$ Una antecedente de este modo de abordar la cuestión lo constituyen los trabajos que se originaron en torno al extinto Centro de Investigación en Ciencias Sociales (CICSO).

${ }^{7}$ Luciana Carreño. "Los caminos de la Reforma Universitaria. Sociabilidad y vida estudiantil en los centros de estudiantes de la Universidad de Buenos Aires (1900-1918). Quinto Sol. Revista de Historia, Volumen 22, $\mathrm{N}^{\circ} 1$. La Pampa, 2018, pp. 1-22.

8 Sobre todo este período en la UBA véase Juan Sebastián Califa. Reforma y revolución: la radicalización política del movimiento estudiantil de la UBA 1943-1966. Buenos Aires, Eudeba, 2014.
} 


\section{¿Centros o cuerpos de delegados? Las luchas estudiantiles de los años setenta frente al debate acerca de las formas organizativas. El caso de la UBA}

atisbo de politización estudiantil izquierdista. Así, junto a la intervención universitaria de 1966, que puso fin a la autonomía y al cogobierno, estas entidades fueron arrasados, clausurando sus locales universitarios. La rica vida gremial que propiciaron, la cual abarcaba desde variadas comisiones de cultura hasta provisión de servicios esenciales para los estudiantes como impresión de apuntes y comedores que abarataban su tránsito universitario, fueron suprimidas.

De este modo, removiendo los pilares universitarios inspirados en la Reforma de 1918, la dictadura creyó acabar con la radicalización reformista, leída como sinónimo de ascenso comunista. La "Ley Orgánica de las Universidades Nacionales" 17.245 sancionada el 21 de abril de 1967 redujo el gobierno de las casas de altos estudios a los profesores de mayor jerarquía, concediéndoles voz pero no voto a los estudiantes. ${ }^{9}$ El representante electo, además, debía ser elegido entre los alumnos del último año y sólo quienes tuvieran aprobada al menos la mitad de la carrera podrían sufragar. En relación a los centros de estudiantes, la nueva legislación, que hacía recordar las normativas sancionadas bajo el primer peronismo, admitía su existencia, pero advertía que no podrían realizar ninguna clase de actividad política. En definitiva, la reconfiguración mentada, al excluir la política de su seno, implicaba la destrucción de los centros tal cual se había organizado hasta entonces. Si bien esta ley nunca se aplicó por completo, sus considerandos moldearon de hecho el proceder de los interventores universitarios. Sólo el cambio de relaciones de fuerzas revirtió esta situación.

Precisamente, con el recrudecimiento de las luchas estudiantiles a principios de la nueva década, en el marco del ascenso de masas imperante, los centros volvieron a la palestra. Su relanzamiento, fiel a la historia, lo llevaron adelante las fuerzas de identidad reformista. Dentro de este arco político variopinto, los comunistas se destacaron otra vez, especialmente en la UBA, por el entusiasmo empeñado en esta labor. El núcleo de la estrategia del Movimiento de Orientación Reformista (MOR) residía en alcanzar su dirección. No era una tarea sencilla, ya que la represión dictatorial los había tenido como blanco predilecto. Esta labor, por cierto, le permitiría a los comunistas recolocarse en el movimiento estudiantil, cuestión que resultaba vital tras la ruptura de su juventud durante 1967 que le había enajenado al partido la mayoría de los amplios apoyos que congregaba en el mundo estudiantil. ${ }^{10}$

\footnotetext{
9 Este cuerpo legal es recogido y analizado por Emilio Mignone, quien fuera con posterioridad funcionario de tal dictadura. Al respecto véase Política y Universidad. El Estado legislador. Buenos Aires, Lugar Editorial, 1998, p. 48 y ss.

${ }^{10}$ Sobre la trayectoria en el siglo XX de esta fuerza política puede verse La Fede. Alistándose para la revolución, La Federación Juvenil Comunista 1921-2005. Buenos Aires, Sudamericana, 2009 y, más específicamente acerca de este cisma, Juan Sebastián Califa. "Del Partido Comunista al Partido Comunista Comité Nacional de Recuperación Revolucionaria en la Argentina de los años sesenta. Una escisión con marca universitaria". Revista Izquierdas, $\mathrm{N}^{\circ}$ 24. Santiago de Chile, julio 2015, pp. $173-$ 204.
} 
En la Facultad de Derecho, por ejemplo, durante septiembre de 1969 la recientemente fundada Agrupación Universitaria Reformista de Estudiantes (AURE) convocó a una asamblea que designó a una comisión directiva organizadora para relanzar el centro. A comienzos de 1970 las luchas por ampliar el ingreso a la institución ayudaron a reagrupar al alumnado, revirtiendo la dispersión reinante. ${ }^{11}$ Una vez que estas confrontaciones cesaron tras la victoria parcial, una nueva asamblea estudiantil dispuso realizar elecciones del centro. Entre las propuestas del AURE figuraban los cursos de promoción y exámenes mensuales, supresión del ingreso limitativo y antipedagógico, derogación de la ley universitaria, y diversos reclamos por la autonomía universitaria, el gobierno tripartito de los tres claustros y el fin de la dictadura. ${ }^{12}$ Con esta campaña la agrupación comunista se alzó con la victoria por la mínima diferencia, 501 votos a 500, frente al Movimiento de Auténtica Reforma Universitaria (MARU) alineado con la Franja Morada radical.

Para afianzarse en las facultades, los comunistas se volcaban a una tarea gremial que los universitarios apreciaban mucho, pero que otros sectores de la militancia, imbuidos en la discusión político nacional, dejaban sumida en un segundo plano. El fomento de la lucha corporativa tenía en Ernesto Giudici, viejo cuadro del PC, su mentor. Bajo su dirección, la Comisión Nacional Universitaria del partido había aclarado que los centros constituían formas organizativas sobresalientes en la lucha estudiantil. ${ }^{13}$ Un mes más tarde en el lanzamiento de la Coordinadora de Agrupaciones Reformista (CAR) adherida al MOR, que reunió unos cincuenta grupos de todo el país, se sostuvo que "la dictadura tiene aliados en el seno del mismo movimiento estudiantil: son los sectores (incluyendo a la actual mayoría de la Junta Ejecutiva de la FUA) que pretenden disolver Centros y Federaciones, destruir a la FUA, dejar a los estudiantes sin organización representativa permanente."14

Esta estrategia, sin embargo, colisionaría con mayores obstáculos. En la Facultad de Ciencias Exactas y Naturales, antecedido por la vieja estructura sepultada por la dictadura -aquí existieron históricamente tres centros-, llegaron a funcionar dos entidades al unísono hasta comienzos de 1970, predominando finalmente el MOR una vez que la representación del alumnado fue asumida por un centro único. ${ }^{15}$ Mucho más tortuosa resultó la aplicación de esta táctica en la politizada Facultad de Filosofía y Letras. En esta casa, la convocatoria electoral a fines de 1970 reunió apenas a dos agrupaciones, venciendo la Lista Violeta comunista con 525 votos sobre 605 emitidos. ${ }^{16}$ Los otros grupos de izquierda, frente

\footnotetext{
11 "Para asegurar el ingreso a Derecho", en Juventud. Órgano de la Federación Juvenil Comunista, № 8, septiembre de 1970 (CEDINCI).

12 Volante de AURE: ¿Para qué un centro de estudiantes?" (ACEN, caja 20).

13 “La línea de los comunistas en la Universidad", en Nuestra Palabra, № 999, 26 de agosto, p. 4 (CEDINCI).

14 “Ahora, en la Universidad", en Juventud. Órgano de la Federación Juvenil Comunista, año XXIIII, № 13 (355), p. 8 (CEDINCI).

${ }^{15}$ Beatriz Baña et. al. Historia de la Facultad de..., Op. Cit., pp. 233-252.

16 "Jaque al gobierno en la Universidad, en Nuestra Palabra, № 1066, 8 de diciembre de 1970 (CEDINCI).
} 


\section{¿Centros o cuerpos de delegados? Las luchas estudiantiles de los años setenta frente al debate acerca de las formas organizativas. El caso de la UBA}

a esta "maniobra", se abstuvieron. ${ }^{17}$ Por ello, aunque los comunistas se contentaron con duplicar sus votos, su influencia aquí seguía siendo baja.

Las peripecias de los comunistas en la Facultad de Arquitectura ilustran más nítidamente la estrategia y sus dificultades. El presidente de la entidad local, el militante del Frente de Agrupaciones Universitarias de Izquierda (FAUDI) Daniel Laufer, había sido secuestrado por personal de los servicios de inteligencia en Bahía Blanca a fines de julio de $1970 .{ }^{18}$ Frente a su encarcelamiento, Fernando Nadra, comunista y vicepresidente de la entidad, tomó el mando del centro. Los militantes del FAUDI, indignados, calificaron el hecho como una usurpación que derivó en su expulsión, con amplio respaldo del arco militante. Para los comunistas, en cambio, cumplía la legalidad estipulada por el estatuto del centro. ${ }^{19}$ Más allá de establecer quién poseía la razón, lo cierto es que era tan clara la voluntad de los "bolches" para acceder a la dirección de los centros, como riesgoso caer en un vacío de legitimidad que las tácticas de su estrategia conllevaban.

Finalmente, el avance en los comicios de centros de 1970 cosechó para los comunistas más de 4.000 de los 6.531 votos emitidos en la UBA. ${ }^{20}$ Pese a que el caudal de votantes fue pequeño, resultó suficiente para relanzar la Federación Universitaria de Buenos Aires (FUBA), extinta hace siete años ${ }^{21}$ En el plano nacional, con demás triunfos, a mediados de noviembre el MOR convocó al Congreso Extraordinario de la Federación Universitaria Argentina (FUA), iniciado en Buenos Aires para luego trasladarse a La Plata. ${ }^{22}$ Según su prensa, 130 delegados y 17 observadores, surgidos de 46 facultades, rodeados de 1.000 personas en la barra, proclamaron el regreso del reformismo a la federación nacional. El IX Congreso de

\footnotetext{
17 Un comunicado firmado por estos sostenía: "Repudiar todo intento de la agrupación L.V.R. y su acólito sumiso, el MAP, de realizar elecciones de carácter netamente divisionistas y como burda estafa al estudiantado, respondiendo a burdos intereses de grupo y con la sola justificación de buscar a cualquier precio, aún el de la división del estudiantado, de hacer un mini-sello sin representatividad ninguna para usarlo a discreción y en supuesta representación de los estudiantes, poniéndolo al servicio de su política pro-oligárquica." Volante "La Junta Electoral al estudiante de Filosofía y Letras", noviembre de 1970 (ACEN, caja 20).

18 BDB, sección junio de 1970, p. 20. Base de datos construida por Pablo Bonavena (1990/2), Las luchas estudiantiles en Argentina 1966/1976, Informe de Beca de Perfeccionamiento, Secretaría de Ciencia y Técnica, Universidad de Buenos Aires (de aquí en más BDB). En el caso de Buenos Aires, esta base que realiza una pormenorizada reconstrucción diaria de los acontecimientos cuenta con información de La Nación, Clarín, La Opinión, La Prensa, Noticias, El Mundo, Mayoría, Crónica (matutino y verpertino), El Cronista Comercial y La Razón. Puede consultarse en el área de Conflicto Social del Instituto de Investigaciones "Gino Germani" de la UBA.

19 "Los sucesos en la Facultad de Arquitectura de Bs. Aires", en Nuestra Palabra, № 1047, 28 de julio de 1970, p. 4 y "Por una FUA renovada. Hacia el congreso extraordinario de la FUA", en Juventud. Órgano de la Federación Juvenil Comunista, año XXIV, № 11 (369), 31 de octubre de 1970, p. 5 (CEDINCI).

${ }^{20}$ Jorge Pereyra: “Hacia el IX Congreso de la Federación Juvenil Comunista”, en Nueva Era, № 1, enero de 1971, pp. 70-74, p. 72 (CEDINCI).

21 “Capital", en Vocero de la FUA. Órgano de la Federación Universitaria Argentina, № 2, marzo de 1971 (CEDINCI).

22 "Volvió la Reforma a la dirección de la FUA", en Nuestra Palabra, № 1064, 24 de noviembre de 1970 (CEDINCI).
} 
la FUA funcionó de acuerdo a los lineamientos que estipuló el año anterior dicha federación. ${ }^{23}$ Sin embargo, esta decisión dejó prácticamente marginados a los comunistas del resto de la militancia estudiantil que no acompañaron el cónclave por ellos convocado. De este modo, la llamada "FUA La Plata" tendría por rival a la "FUA Córdoba", bautizada de este modo por la reunión de sus opositores reformistas en esa ciudad a fines de 1970.

\section{Surgen los cuerpos de delegados}

Al reanudarse la actividad académica a comienzos de 1971 el problema del acceso a las casas de altos estudios revivió. Bajo la bulla de las nuevas protestas, se conoció en marzo la decisión de la dictadura de preservar el sistema de ingreso, dando libertad de aplicación a cada facultad. Gran indignación causó entre los rectores de las universidades nacionales la actitud de su par cordobés, Olsen Ghirardi, quien, atento a los tiempos políticos de su provincia, eliminó el examen de admisión. Para el rector porteño Andrés Santas, se trataba de "una clara actitud contra la ley universitaria". ${ }^{24}$

En ese contexto, el plan de las autoridades de trasladar las carreras de Sociología, Psicología, Antropología y Educación a una nueva Facultad de Ciencias del Comportamiento junto a la controvertida apertura de los concursos (que dejaban afuera a muchos docentes, como los nucleados en las cátedras nacionales peronistas) generaba malestar en la Facultad de Filosofía y Letras. Cuando a ello se sumó la decisión de sus autoridades de mantener el examen de ingreso, sus estudiantes ensayaron una movilización que resultó abortada por la policía. En ese interín, recogiendo tales demandas, se formó entre los estudiantes la Mesa de Lucha, constituida por los peronistas del Frente de Estudiantes Nacionales (FEN), los maoístas de FAUDI y TUPAC, los guevaristas de Carta Abierta y los trotskistas de la TERS (alineados con Política Obrera). ${ }^{25}$ Este espacio, como se verá, sería clave en la conformación del cuerpo de delegados.

Entretanto, el 26 de marzo, el general Agustín Lanusse, representante de la fracción más ilustrada del ejército y la burguesía, asumió la presidencia de la nación. La expulsión de Marcelo Levingston se vio precipitada a partir del llamado "Viborazo" o "segundo Cordobazo", hechos que volvieron a unir a estudiantes y obreros en las calles, carcomiendo la poca legitimidad que detentaba el poder militar de cara a la sociedad. Por ello, el nuevo mandatario propugnó un plan de apertura política a nivel general, con la colaboración del nuevo Ministro del Interior, el radical Arturo Mor Roig, autorizando el funcionamiento de los comités de los partidos políticos e

\footnotetext{
${ }^{23}$ En agosto el MOR en un comunicado había sostenido que la "mayoría" realizó el año pasado una parodia de Congreso; explotando la clandestinidad redujo el número de delegados e impugnó y excluyó a otros. Señalaba que pese a este fraude no pudo llevar su antirreformismo hasta el final y fue derrotado, debiendo convocar a tal Congreso Extraordinario para 1970. "Llamamiento del MOR. Por un verdadero Congreso de la FUA", agosto de 1970 (CEDINCI).

24 “Universidad. Los fuegos tempranos", en Primera Plana, Año IX, № 423, 9 marzo de 1971, p. 15 (HCN).

${ }^{25}$ BDB, sección marzo de 1971, p. 8 (BDB).
} 


\section{¿Centros o cuerpos de delegados? Las luchas estudiantiles de los años setenta frente al debate acerca de las formas organizativas. El caso de la UBA}

impulsando el "Gran Acuerdo Nacional” (GAN) como salida pactada de la dictadura. ${ }^{26}$ Según sus palabras: “... la política consistía, por un lado, en la represión de los irrecuperables, pero, por otro, en privar de oxígeno político a la subversión.”27

En el plano educativo la dictadura impulsaba una reforma que disparó un ciclo de huelgas docentes, por su carácter "privatista" y "confesional", contando con el apoyo del movimiento estudiantil secundario. ${ }^{28}$ Las universidades nacionales también estaban comprendidas al plantear el gobierno su normalización a través de la constitución de Consejos Académicos sin participación estudiantil. Con esa preocupación, los universitarios se plegaron con fuerza a las protestas, sumándose al pedio de renuncia del ministro. El 13 de mayo, bajo ese ambiente convulsionado, Luis Cantini dimitió al Ministerio de Educación.

Gustavo Malek, actual rector de la bahiense Universidad Nacional del Sur, lo reemplazó. ${ }^{29} \mathrm{Al}$ asumir, declaró que los estudiantes participarían en el régimen universitario. En ese marco, las elecciones de profesores para integrar los Consejos Académicos recibieron el apoyo del liberal Movimiento Universitario de Centro (MUC) de Derecho y los centros de Veterinaria y Odontología de la UBA. ${ }^{30}$ Sin embrago, el amplio abanico de agrupaciones juveniles se opuso, restándoles fuerza a la iniciativa oficialista.

En esta atmósfera de apertura, el duro Santas fue remplazado por el geólogo Bernabé Quartino el 22 de julio de 1971. Con pasado peronista, el nuevo rector de la UBA se mostraba embelesado por el "espíritu dialoguista" que emanaba del gobierno, aspirando a cercar con esta política a los más díscolos. Tal es así que en su asunción sostuvo: "Los alumnos forman parte de lo que podríamos llamar consulta universitaria; su opinión importa porque no constituyen un objeto sino un objetivo."31

En medio de tales tensiones y transformaciones, la Facultad de Filosofía y Letras se fue consolidando como un "bastión rebelde" a partir de la acción convergente de estudiantes y docentes, tanto de las cátedras nacionales peronistas como de la flamante agrupación de izquierda 29 de Mayo, con influjo del maoísmo.

\footnotetext{
${ }^{26} \mathrm{Al}$ respecto véase Marcos Novaro. Historia de la Argentina (1955-2010). Buenos Aires, Siglo XXI, 2011, p. 113; Liliana De Riz. Historia Argentina. La política en suspenso 1966/1976. Buenos Aires, Paidós, 2000, p. 105 y Pablo Bonavena, Mariana Maañón, Gloria Morelli, Flabián Nievas, Roberto Paiva y Martín Pascual. Orígenes y desarrollo de la guerra civil en Argentina: 1966-1976. Buenos Aires, Eudeba, 1998, p. 97 y ss.

27 Mi testimonio. Buenos Aires, Lasserre, 1977, p. 163.

${ }^{28} \mathrm{Al}$ respecto véase Laura Graciela Rodríguez. "La reforma educativa del gobierno de Juan Carlos Onganía. Adhesiones y resistencias”, en Valeria Galván y Florencia Osuna, (comps.), Política y cultura durante el "Onganiato". Nuevas perspectivas para la investigación de la presidencia de Juan Carlos Onganía (1966-1970). Rosario, Prohistoria, 2014, pp. 157-175.

29 Sobre su trayecto al frente de dicha institución véase Edgardo Fernández Stacco. Abandono a la contemplación. Apuntes para la historia de la Universidad Nacional del Sur. Buenos Aires, Editorial Universitaria Rioplatense, 2009, p. 311 y ss.

30 BDB, sección mayo de 1971, p. 20.

31 “Conceptos del rector Quartino al asumir al cargo", en Gaceta Universitaria (UBA), № 1, Año 1, julio 1972, p. 2 (CEDINCI).
} 
Desde esta casa de estudio se habían llevado adelante la mayor cantidad de acciones de protesta contra el régimen en comparación con el resto de las facultades de la UBA. ${ }^{32}$ En ese sentido, su militancia se había ganado un lugar destacado dentro de la ofensiva antidictatorial en boga.

En este marco, el 10 de junio de 1971 una multitudinaria asamblea de estudiantes resolvió asumir el gobierno de la institución, desconociendo al decano y ocupando el edificio para garantizar el desarrollo de las tareas académicas. ${ }^{33}$ Una nueva entidad llevó adelante la lucha: el cuerpo de delegados de cursos, que se había ido moldeando sobre la base de la Mesa de Lucha abocada a la disputa por ampliar el ingreso universitario. Su programa se erigía: "1- Contra la división de carreras; 2Contra el plan de la intervención y todo plan de estudios elaborado sin participación del estudiantado; 3- Contra la colaboración o negociación con las autoridades; 4- Por la elaboración de planes de alternativa al servicio del proceso de liberación; 5Contra los exámenes de ingreso; 6- Contra la represión y la tortura; por el levantamiento de sanciones y expulsiones, la libertad de compañeros presos y detenidos políticos; 7- Contra la dictadura y sus variantes golpistas o electorales". ${ }^{4}$

Los cuerpos de delegados no eran, por cierto, un producto original de Buenos Aires. Esta experiencia se había iniciado en los claustros cordobeses a comienzos de 1971, en buena medida viéndose al espejo del llamado "sindicalismo combativo" con arraigo en la industria automotriz. ${ }^{35}$ Su nacimiento se enraizaba con la "... creciente demanda de autonomía y democracia de base, que se afirmó como un código común sobre todo entre los sectores juveniles" descrita por Mónica Gordillo. ${ }^{36}$ Según Pablo Bonavena, en el único trabajo que se ha explayado sobre esta experiencia, de carácter descriptivo ya que el autor a diferencia de lo que aquí se propone renuncia a trazar una explicación sobre su evolución, fue en Buenos Aires donde su actividad alcanzó mayores bríos. ${ }^{37}$ Nicolás Dip, en un libro dedicado al peronismo universitario, señaló lo central que resultó esta nueva entidad para un sector que

\footnotetext{
${ }^{32} \mathrm{Al}$ respecto véase Pablo Bonavena, Juan Sebastián Califa y Mariano Millán. “ ¿Ha muerto la Reforma? La acción del movimiento estudiantil porteño durante la larga década de 1966 a 1976". Archivos de la historia del movimiento obrero y la izquierda, Año VI, $\mathrm{N}^{\circ} 12$. Buenos Aires, marzo de 2018, pp. 7395 , p. 82 , tabla ${ }^{\circ} 1$.

33 BDB, sección junio de 1971, p. 8.

${ }^{34}$ Los orígenes de esta organización fueron retratados en "Estudiantes. Filo, contrafilo y punta", en Confirmado, Año II, № 314, 23 al 29 de junio de 1971, pp. 20-21 y "Universidad. La fórmula del gatopardo", en Panorama, № 215, Año 9, 8 al 14 de junio de 1971, p. 13 (HCN). Me respaldo en esta fuente para las afirmaciones que siguen acerca de esta casa de estudios.

${ }^{35}$ Véase Rubén Levemberg y Daniel Merolla. Un solo grito. Crónica del movimiento estudiantil universitario de 1918 a 1988. Buenos Aires, Federación Universitaria de Buenos Aires, 1988, p. 96. y Roberto Ferrero. Historia Crítica del Movimiento Estudiantil de Córdoba. Tomo III (1955-1973). Córdoba, Alción, 2009, pp. 221-276.

36 "Protesta, rebelión y movilización: de la resistencia a la lucha armada, 1955-1976", en Daniel James, (dir.), Nueva Historia Argentina. Tomo 9: Violencia, proscripción y autoritarismo (1955-1976). Buenos Aires, Sudamericana, pp. 329-380, p. 362.

37 “¿Centros de estudiantes o cuerpos de delegados? La génesis del 'doble poder' estudiantil en Buenos Aires durante la década del '70", ponencia presentada en V Jornadas de Estudio y Reflexión sobre el Movimiento Estudiantil Argentino y Latinoamericano, Departamento de Ciencias Sociales, Universidad Nacional de Luján, Luján, 2012 [en línea http://conflictosocialiigg.sociales.uba.ar/wpcontent/uploads/sites/72/2018/05/4-Bonavena.pdf] [Consulta: 23/7/2018].
} 


\section{¿Centros o cuerpos de delegados? Las luchas estudiantiles de los años setenta frente al debate acerca de las formas organizativas. El caso de la UBA}

estaba dando nuevos pasos. ${ }^{38}$ Por su parte, muchos contemporáneos que activaron en sus filas creyeron ver en los cuerpos de delegados verdaderos órganos de doble poder que abrían una lucha con los interventores en torno a su efectiva dirección de las facultades. Claro está que en momentos donde la dictadura se batía en retirada, este desafío se hacía más creíble para sus protagonistas y también para aquellos a los que iba dirigido.

La novel organización de Filosofía y Letras funcionaba de modo asambleario, reuniendo en sus comienzos más de doscientos representantes de cursos quienes tenían la voz cantante en las resoluciones. Sometido a la lucha de tendencias, sobresalían en sus filas las agrupaciones de la izquierda marxistas alejadas años atrás del ideario reformista $\mathrm{y}$, en menor medida, un ramillete de pequeños grupos peronistas, siempre reacios a la reforma y los centros. En definitiva, se trataba de un compendio de organizaciones plausibles de ubicarse dentro de lo que algunos autores han denominado "nueva izquierda". ${ }^{39}$ Estos militantes desconocían así a las federaciones y centros - de hecho ese año lograron enterrar al Centro de Estudiantes de Filosofía y Letras-, estando sus mentores convencidos de que la radicalización en marcha iría sepultando tales entidades de cuño reformista.

En los meses siguientes, los cuerpos de delegados aumentaron su reto a la dictadura. Para entonces, habían conseguido cierta expansión en el país. En la Capital Federal se estaba recreando una experiencia tal en la Escuela de Bellas Artes Prilidiano Pueyrredón, que se acercaría a sus pares porteños. Con este impulso, advirtiendo que la "Revolución Argentina" se encontraba en tiempo de descuento, la izquierda estudiantil trataba de preservar la iniciativa política planteando una disputa en torno a su autoridad en cada unidad académica. Desde sus filas, se cuestionaba ásperamente los profesores identificados con la dictadura, a quienes se intentaba remover, imponiendo otros afines a los jóvenes opositores.

Un volante de los maoístas de la Tendencia Universitaria Popular Antimperialista Combatiente (TUPAC, brazo universitario de Vanguardia Comunista) de Filosofía y Letras, fechado el 25 de agosto, constituye un testimonio clave. ${ }^{40}$ El texto arrancaba señalando que el anhelo de la dictadura de desmembrar la facultad había sido derrotado, tras constituirse una inédita alianza obrero-estudiantil que inauguró el doble poder vernáculo. Sin embargo, los intentos de parte de las autoridades no cesarían, iniciándose el segundo cuatrimestre en un marco general de parálisis en quince materias, la mayoría de Psicología y Sociología. Frente a este panorama proponían: desconocer el régimen de correlatividades, reinstalar a los docentes cesanteados, ignorar los concursos problemáticos, impulsar el retiro de las fuerzas

\footnotetext{
38 Libros y alpargatas. La peronización de estudiantes, docentes e intelectuales de la UBA (1966-1974). Rosario, Prohistoria, 2017, p. 90.

39 Para una recapitulación reciente y completa de este concepto véase María Cristina Tortti, (dir.). $L a$ nueva izquierda argentina (1955-1976): socialismo, peronismo y revolución. Rosario, Prohistoria, 2014.

40 ACEN, caja 20.
} 
represivas y bregar por reorganizar el cuerpo de delegados sobre la base de los cursos.

En paralelo, cuando el cuerpo de delegados de Filosofía y Letras comenzaba a atravesar corrosivas querellas internas, la Facultad de Arquitectura vio surgir su propio cuerpo de delegados. La arquitectura era una disciplina particularmente afectada por el proceso de radicalización hacia la izquierda: la relevancia que había adquirido la discusión sobre la vivienda social en el mundo, así como la cursada en talleres, politizaba sobremanera a los estudiantes. ${ }^{41}$

Dentro del cuerpo de delegados de esta facultad, los maoístas de FAUDI y TUPAC junto a los peronistas de la Tendencia Universitaria Popular de Arquitectura y Urbanismo (TUPAU) y de la Unión Nacional de Estudiantes (UNE) sobresalían. Una crónica periodística retrataba así su funcionamiento: “Cada grupo de taller equivalente a la comisión de prácticos- elige su portavoz. Los 350 forman el Cuerpo de Delegados; de ellos surgen los 28 miembros de la Mesa Ejecutiva. Crearán, por fin, una comisión directiva política más pequeña y ágil, ungida por voto directo y capaz de reemplazar a los bolches moscovitas 'burocratizados' del Centro de Estudiantes." 42

En lo que quedaba del año sus acciones se harían sentir. El 9 de septiembre de 1971, la acumulación de fuerzas que conquistó, le permitió al cuerpo de delegados de Arquitectura impulsar el levantamiento de las clases, inaugurando en su lugar cursos paralelos, ante lo que las autoridades decretaron el cierre de la casa. ${ }^{43}$ En respuesta, los estudiantes reprobaron por engañoso los concursos convocados y bregaron por admitir únicamente a los catedráticos por ellos designados. Bajo este clima, el 15 de septiembre, el decano Raúl Grego clausuró la facultad, poniéndola bajo custodia policial. ${ }^{44}$ De inmediato, estudiantes y docentes díscolos de la casa se movilizaron exigiendo su reapertura. El presidente Lanusse, al observar el avance del "poder paralelo" en el país, afirmó sin titubeos que si su freno: “... no se logra por la acción de docentes y autoridades responsables, cabe formularse la reflexión de que puede resultar conveniente cerrar determinadas casas de estudio, evitando que sigan constituyendo un foco de subversión y caos."45

Durante octubre, las autoridades de Arquitectura ensayaron una nueva respuesta a los insurrectos bajo una modalidad de participación controlada. Con ese

\footnotetext{
${ }^{41}$ La reconstrucción de una singular experiencia de aprendizaje en la Universidad Nacional de Córdoba, con su impacto en otras casas de altos estudios, retrata bien esta situación en la Argentina. Véase Juan Sebastián Malecki. “Crisis, radicalización y política en el Taller Total de Córdoba, 19701975”. Prohistoria, Año XIX, N²5. Rosario, junio de 2016, pp. 78-103.

42 “Estudiantes. El amanecer escatológico", en Primera Plana, 21 de septiembre, № 451, Año IX, p. 12 (HCN).

${ }^{43}$ BDB, sección septiembre de 1971, p. 18.

${ }^{44}$ BDB, sección septiembre, p. 24.

${ }^{45}$ Una nota periodística explicaba que estas recomendaciones las habían recogido los decanos en el memorándum emitido desde la presidencia, intitulado Orientación al Consejo de Rectores, que aconsejaba la clausura de facultades antes de que se convirtieran en "focos de subversión y caos". Esa sugerencia la habían recibido los rectores cuando mantuvieron la entrevista con Lanusse el 21 de septiembre. De acuerdo a "Universidad. Poder paralelo o clausura", en Confirmado, № 330, Año VII, 12 al 18 de octubre, pp. 18-22 (HCN).
} 


\section{¿Centros o cuerpos de delegados? Las luchas estudiantiles de los años setenta frente al debate acerca de las formas organizativas. El caso de la UBA}

fin organizaron comicios estudiantiles para elegir ocho delegados de taller que sumados a docentes y autoridades conformarían comisiones abocadas a examinar la reestructuración de la carrera y el plan de estudios. No obstante, debido a la escasa concurrencia, las urnas debieron ser levantadas. Frente a esta situación, el decano hizo suyo el consejo presidencial al decretar el 20 de octubre la culminación del ciclo lectivo. ${ }^{46}$

En respuesta, las asambleas estudiantiles plantearon que el cierre los perjudicaba “... porque no quieren reconocer lo que estamos haciendo". ${ }^{47}$ Resolvieron entonces repudiar la declaración de Grego que desconocía al cuerpo de delegados, y convocaron a movilizarse en su contra. Reafirmaron además “... la posición contra la dictadura, el gran acuerdo nacional y todo golpe o variante electorera con nombres y apellidos: Hora del Pueblo y E.N.A. [Encuentro Nacional de los Argentinos]", esto es, los dos frentes políticos que de cara a las expectativas de retorno democrático motorizaban peronistas y radicales, por un lado, y comunistas, por otro.

Con este mandato, el 25 de octubre, unos 600 estudiantes ocuparon las inmediaciones del decanato, entrevistándose un grupo con el titular de la casa. ${ }^{48}$ Mientras tanto, la asamblea estudiantil en la sede de Ciudad Universitaria comunicó que el cierre de la facultad implicaba la imposibilidad de “... recomponer la estructura que los estudiantes declararon caduca al iniciar el movimiento, pero que esa medida significa en la práctica la pérdida del año...". Al día siguiente, una delegación fue recibida por el rector, entregándole un "pliego de exigencias". Pese a que los estudiantes se retiraron defraudados, el cauce del diálogo que el encuentro abrió inauguró toda una política de acción hacia los insurrectos que complementaría la recurrente represión policial.

En simultáneo, el 27 de octubre en Filosofía y Letras se produjo un paro, convocado por su cuerpo de delegados. ${ }^{49}$ Ese día una asamblea de los estudiantes de Antropología repudió la clausura del Museo Etnográfico, cuyo acto fue evaluado como "pase previo al cierre general de la casa de estudios". En esa jornada se desarrolló además un ampuloso "juicio a la represión". Pese a esta acción de protesta, el retraimiento del cuerpo de delegados ya era vox populi.

En tanto, ante la extensión del conflicto de Arquitectura el rectorado jugó nuevas cartas en el asunto. Su intervención apuntó a contener la movilización, aislando a los más radicalizados de su seno. Su modo de actuar consistió en propiciar encuentros con el propio cuerpo de delegados. ${ }^{50}$ Se entrevistó además con otras delegaciones, que aunque no poseían tal nivel de organización, se pretendía que tampoco lo alcancen; entre ellas se destacó una representación de Ciencias

\footnotetext{
46 Esto lo hizo retroactivo a la segunda quincena de agosto, como un modo de desconocer los cursos paralelos impulsados por los estudiantes. "Universidad. La senda estrecha”, en Primera Plana, $\mathrm{N}^{\circ} 456$, año IX, 26 de octubre de 1971, p. 10 (HCN).

47 BDB, sección octubre de 1971, p. 25.

48 BDB, sección octubre de 1971 , p. 29 y ss.

${ }^{49}$ BDB, sección octubre de 1971, p. 32.

${ }^{50}$ BDB, sección noviembre de 1971, p. 3.
} 
Económicas a quien le propuso crear otra cátedra de Economía Laboral, cuestión que venía generando airadas protestas. ${ }^{51}$ Con esta postura dialoguista desde el rectorado se pudo evitar que en otras facultades cobraran vuelo los cuerpos de delegados.

En paralelo, empero, también la represión hacía lo suyo. Por caso, a comienzos de noviembre de 1971 el nuevo decano de Filosofía y Letras, el peronista Antonio Serrano Redonnet, advirtió que si el historiador Alberto Pla se hacía cargo de un curso, como lo habían anunciado los estudiantes díscolos, le iniciaría acciones legales por no ser docente de la casa. ${ }^{52}$ Este tipo de represión, que también padecería su colega Silvio Frondizi, sería completada por una violencia más abierta y descarnada. En lo que sería la última intervención resonante del cuerpo de delegados de Filosofía y Letras, se reclamaría por la aparición de dos estudiantes, militantes de la TERS trotskista. Merced a las protestas que esta entidad propulsó, ambos compañeros aparecieron en una comisaría de Valentín Alsina, donde habían sido alojados sin aviso a causa de sus actos de militancia en la zona. ${ }^{53}$

En simultáneo, el cuerpo de delegados de Arquitectura también empezaría a decaer. Tras conseguir a principios de noviembre que se levanten las mesas de exámenes dispuestas desde el decanato, en vista de que no contemplaban representantes suyos, su intervención caería en picada. ${ }^{54}$ Las presiones del decanato para que los estudiantes voten en nuevas elecciones, bajo amenaza de que de lo contrario no se les permitiría rendir exámenes, consiguieron su anhelo. ${ }^{55}$ Con ello, el decano de esta casa pudo anunciar a comienzos de 1972 que en los comicios de representantes para conformar los cuerpos técnicos y grupos de trabajo encargados de practicar estudios sobre problemas vinculados a la enseñanza habían votado 7.052 alumnos empadronados, 5.317 de ellos de modo positivo. ${ }^{56}$ Los 1.735 que no sufragaron, de los cuales 611 luego presentaron notas de excusación con justificativos, ponían en evidencia la baja recepción que había sufrido el cuerpo de delegados de Arquitectura en donde se había mostrado más fuerte, la base estudiantil. Más allá de que otra fuente al plantear cifras alternativas pone en entredicho tamaño optimismo por parte de estas autoridades, el declive que desde entonces experimentó este cuerpo de delegados resultó un dato irreprochable. ${ }^{57}$

En tanto, con menos vocinglería, los centros de estudiantes venían recobrando protagonismo. A diferencia de los anteriores organismos, estas entidades funcionaban con menos publicidad, pero sin pausa. Los intentos de lanzar cuerpos

\footnotetext{
51 BDB, sección noviembre de 1971, p. 1.

52 BDB, sección noviembre de 1971, p. 2.

53 Sobre este hecho y la represión más en general durante estos años en tal institución véase Juan Sebastián Califa y Mariano Millán. "El movimiento estudiantil como objetivo de la represión. Un estudio sobre el caso de la UBA entre 1966 y 1976". PolHis. Revista Bibliográfica del Programa Interuniversitario de Historia Política, Volumen 8, № 16. Mar del Plata, julio de 2016, pp. 258-295.

${ }^{54}$ BDB, sección noviembre de 1971, p. 5.

55 BDB, sección diciembre de 1971, p. 25.

56 BDB, sección enero de 1972, p. 2. Según otro medio gráfico, la Comisión Curricular encargada de producir reformas constaría de 20 representantes, de los cuales 15 son de los docentes. "Universidad. Remembranzas de ayer", en Primera Plana, 14 de diciembre de 1971, no 463, Año X, p. 15 (HCN). 57 Véase "Universidad. Las bombas y las urnas", en Panorama, n 244, año IX, 28 de diciembre de 1971 al 3 de enero de 1972, p. 15 (HCN).
} 


\section{¿Centros o cuerpos de delegados? Las luchas estudiantiles de los años setenta frente al debate acerca de las formas organizativas. El caso de la UBA}

de delegados en otras facultades habían encontrado en los centros un rival invencible. Paradigmático al respecto resultó lo acaecido en la Facultad de Derecho. La lucha en esta facultad por instalar cátedras paralelas, que compitieran con las que avalaba su decanato, había servido para fortalecer el centro. Incluso en ese contexto el surgimiento de un cuerpo de delegados había sido instrumentado en favor suyo.

En la reconstrucción de tales centros, los comunistas siguieron ocupando un lugar sobresaliente, al contrario de lo que sucedía en los cuerpos de delegados donde no existía tal preeminencia. Los "bolches" triunfaron en las entidades de Ciencias Económicas, Derecho, Medicina, Ciencias Exactas y Naturales, Ingeniería y Farmacia y Bioquímica de la UBA. ${ }^{58}$ No respaldarse casi en exclusiva por el activo más militante, concitando en cambio la adhesión del sector intermedio entre este y la pasividad absoluta, mediante la acción gremial que impulsaron, resultó clave. Imprimir apuntes de las cátedras podía no provocar pasiones, pero en vistas de construir un sujeto político antidictatorial a la larga terminaba siendo más efectivo y concreto que el abstracto y corrosivo debate entre agrupaciones que propiciaban los cuerpos de delegados, tal cual era percibido por los estudiantes menos politizados.

Esta situación, en un contexto donde tuvieron lugar unas setenta elecciones de centros en el país, todo un récord bajo la dictadura, les permitía a los comunistas sentenciar de muerte la idea de que junto a la Reforma Universitaria estas entidades se hallaban en su ocaso. Más bien, la llamada "nueva izquierda" y sus invenciones organizativas se encontraban ahora en esa situación.

\section{Vencedores y vencidos}

La conflictividad social ascendente registrada desde fines de los años sesenta abonó las reyertas internas sobre las formas organizativas más adecuadas para impulsar al movimiento estudiantil opositor a la dictadura. De este modo, la disyuntiva entre centros de estudiantes y cuerpos de delegados de base atravesó la lucha política antidictatorial. La más prolongada prosperidad que disfrutó la primera modalidad organizativa no debiera soslayar, pese a su fugacidad, la intensa actividad desplegada desde los segundos organismos.

El año 1971, como se evocó, marcó el pico de la conflictividad estudiantil. El pasaje de los jóvenes universitarios a la ofensiva popular, junto a las luchas obreras que se venían desatando desde los grandes hechos de masas que hace dos años ponían en jaque a la dictadura, prosiguió en un ascenso vertiginoso. En la UBA, siguiendo este periplo, durante dicho año se registró el mayor número de enfrentamientos protagonizados por sus estudiantes.

\footnotetext{
58 "Universidad: cinco victorias de la unidad", en Nuestra Palabra, № 1114, 8 de noviembre de 1971, sin más datos y "Lo que se fortalece son los centros", en Nuestra Palabra, № 1115, 16 de noviembre de 1971, sin más datos.
} 
En ese marco, la propuesta de los cuerpos de delegados fue vista con creciente interés por parte de organizaciones de izquierda que, pese a registrar cierto crecimiento en los años precedentes, seguían estando por debajo de sus propias expectativas. Sus militantes creían que con los cuerpos de delegados no sólo se podría imponer un "poder paralelo" que venciera a la dictadura en tales unidades académicas, sino que, al mismo tiempo, se podía derrotar a los competidores entronados en los centros de estudiantes, particularmente los comunistas, alcanzado así la ansiada primacía. Desde la óptica de los reformistas, en cambio, estas formas organizativas si bien no debían ser desechadas por completo, tampoco había que sobredimensionarlas, ya que, más allá de su papel en los picos de participación, resultaba muy difícil gestionarlas cuando la masa estudiantil se relajaba, no dejando mucho tras de sí. Los centros, por el contrario, argüían, forjaban un canal más sólido de participación, que incluso, como sucedió en la Facultad de Derecho, podía corresponderse con los cuerpos de delegados, supeditándolos a su dirección. A juzgar por los resultados, la razón abrazó a los segundos.

Sin embargo, no es menos cierto que en el marasmo de la conflictividad universitaria, los cuerpos de delegados pusieron en aprietos a la dictadura. La atención que debió dedicarles Lanusse, tras asumir la primera magistratura, es una prueba de las preocupaciones que su acción deparó en las altas esferas de la política.

Filosofía y Letras, la facultad más politizada de la UBA, vio nacer al cuerpo de delegados en Buenos Aires, siguiendo su huella Arquitectura. Combinadas, ambas formas organizativas, contribuyeron a la retirada de la dictadura en el ámbito universitario. Pero mientras que el reformismo logró expandir a la postre su radio de acción, rehusándose a morir como muchos autores sostienen, las organizaciones que por izquierda disputaban con su militancia, se estancaron e incluso empequeñecieron.

En este contexto, los centros de estudiantes, y no sólo en Buenos Aires, le ganaron la pulseada a los cuerpos de delegados como principales formas organizativas del movimiento estudiantil. De hecho, FAUDI Y TUPAC, dos organizaciones que habían volcado su militancia hacia los cuerpos de delegados, más aún la segunda que los calificaba como la forma organizativa excluyente del movimiento estudiantil, volvieron a participar, con malos resultados, de las elecciones de centros en la UBA a fines de 1972 cuando ya los cuerpos de delegados pasaron al recuerdo.

Tal fue su triunfo que durante 1973, cuando retornaron las urnas en la Argentina, la izquierda peronista se volcó en masa a conquistar los centros, que otrora sus militantes habían despreciado por sus intrincados vínculos con la Reforma Universitaria.

\section{Bibliografía}

Baña, Beatriz; Borches, Carlos; Carnota, Raúl y Díaz de Guijarro, Eduardo. Historia de la Facultad de Ciencias Exactas y Naturales. Universidad de Buenos Aires, 2015. 


\section{¿Centros o cuerpos de delegados? Las luchas estudiantiles de los años setenta frente al debate acerca de las formas organizativas. El caso de la UBA}

Bonavena, Pablo; Maañón, Mariana; Morelli, Gloria; Nievas, Flabián; Paiva, Roberto y Pascual, Martín. Orígenes y desarrollo de la guerra civil en Argentina: 1966-1976. Buenos Aires, Eudeba, 1998.

Bonavena, Pablo. “¿Centros de estudiantes o cuerpos de delegados? La génesis del 'doble poder' estudiantil en Buenos Aires durante la década del '70", ponencia presentada en $V$ Jornadas de Estudio y Reflexión sobre el Movimiento Estudiantil Argentino y Latinoamericano, Departamento de Ciencias Sociales, Universidad Nacional de Luján, Luján, 2012 [en línea http://conflictosocialiigg.sociales.uba.ar/wpcontent/uploads/sites/72/2018/05/4-Bonavena.pdf] [Consulta: 23/7/2018]. Bonavena, Pablo; Califa, Juan Sebastián y Millán, Mariano. “¿Ha muerto la Reforma? La acción del movimiento estudiantil porteño durante la larga década de 1966 a 1976". Archivos de la historia del movimiento obrero y la izquierda, Año VI, N 12. Buenos Aires, marzo de 2018, pp. 73-95.

Buchbinder, Pablo. Historia de las universidades argentinas. Buenos Aires, Sudamericana, 2005.

Califa, Juan Sebastián. Reforma y revolución: la radicalización política del movimiento estudiantil de la UBA 1943-1966. Buenos Aires, Eudeba, 2014.

Califa, Juan Sebastián. "A los golpes con el golpe". Conflicto Social. Revista del Programa de Investigaciones sobre Conflicto Social, $\mathrm{N}^{\circ}$ 13. Buenos Aires, 2015, pp. 89-115.

Califa, Juan Sebastián. “Del Partido Comunista al Partido Comunista Comité Nacional de Recuperación Revolucionaria en la Argentina de los años sesenta. Una escisión con marca universitaria". Revista Izquierdas, $\mathrm{N}^{\circ} 24$. Santiago de Chile, julio 2015, pp. 173-204.

Califa, Juan Sebastián y Millán, Mariano. "El movimiento estudiantil como objetivo de la represión. Un estudio sobre el caso de la UBA entre 1966 y 1976". PolHis. Revista Bibliográfica del Programa Interuniversitario de Historia Política, Volumen 8, № 16. Mar del Plata, julio de 2016, pp. 258-295.

Carreño, Luciana. "Los caminos de la Reforma Universitaria. Sociabilidad y vida estudiantil en los centros de estudiantes de la Universidad de Buenos Aires (19001918). Quinto Sol. Revista de Historia, Volumen 22, N 1 . La Pampa, 2018, pp. 1-22.

De Riz, Liliana. Historia Argentina. La política en suspenso 1966/1976. Buenos Aires, Paidós, 2000.

Dip, Nicolás. Libros y alpargatas. La peronización de estudiantes, docentes e intelectuales de la UBA (1966-1974). Rosario, Prohistoria, 2017.

Ferrero. Historia Crítica del Movimiento Estudiantil de Córdoba. Tomo III (19551973). Córdoba, Alción, 2009..Fernández Stacco, Edgardo. Abandono a la contemplación. Apuntes para la historia de la Universidad Nacional del Sur. Buenos Aires, Editorial Universitaria Rioplatense, 2009.

Gilbert, Isidoro. La Fede. Alistándose para la revolución, La Federación Juvenil Comunista 1921-2005. Buenos Aires, Sudamericana, 2009.

Gordillo, Mónica. "Protesta, rebelión y movilización: de la resistencia a la lucha armada, 1955-1976”, en Daniel James, (dir.), Nueva Historia Argentina. Tomo 9: Violencia, proscripción y autoritarismo (1955-1976). Buenos Aires, Sudamericana, pp. 329-380. 


\section{Juan Sebastián Califa}

Mignone, Emilio Política y Universidad. El Estado legislador. Buenos Aires, Lugar Editorial, 1998.

Rodríguez, Laura Graciela. "La reforma educativa del gobierno de Juan Carlos Onganía. Adhesiones y resistencias”, en Valeria Galván y Florencia Osuna, (comps.), Política y cultura durante el "Onganiato". Nuevas perspectivas para la investigación de la presidencia de Juan Carlos Onganía (1966-1970). Rosario, Prohistoria, 2014, pp. 157-175.

Tortti, María Cristina, (dir.). La nueva izquierda argentina (1955-1976): socialismo, peronismo y revolución. Rosario, Prohistoria, 2014.

Lanusse, Agustín. Mi testimonio. Buenos Aires, Lasserre, 1977.

Malecki, Juan Sebastián. “Crisis, radicalización y política en el Taller Total de Córdoba, 1970-1975”. Prohistoria, Año XIX, N²5. Rosario, junio de 2016, pp. 78103.

Millán, Mariano. Entre la Universidad y la política. Los movimientos estudiantiles de Corrientes y Resistencia, Rosario, Córdoba y Tucumán durante la "Revolución Argentina" (1966-1973). Tesis de Doctorado. Buenos Aires, Facultad de Ciencias Sociales de la Universidad de Buenos Aires, 2013.

Novaro, Marcos. Historia de la Argentina (1955-2010). Buenos Aires, Siglo XXI, 2011. Universidad de Buenos Aires. La Noche de los Bastones Largos: cincuenta años 19662016. Buenos Aires, Eudeba, 2016.

\section{Fuentes}

Archivo del Centro de Documentación e Investigación de la Cultura de Izquierdas (CEDINCI).

Archivo del Centro de Estudios Nacionales bajo el resguardo de la Biblioteca Nacional (ACEN).

Base de datos construida por Pablo Bonavena (1990/2), Las luchas estudiantiles en Argentina 1966/1976, Informe de Beca de Perfeccionamiento, Secretaría de Ciencia y Técnica, Universidad de Buenos Aires. Puede consultarse en el área de Conflicto Social del Instituto de Investigaciones "Gino Germani” de la UBA.

Hemeroteca del Congreso de la Nación (revistas consultadas: Panorama, Primera Plana y Confirmado) (HCN).

Recibido: 21/06/2018

Evaluado: $01 / 07 / 2018$

Versión Final: 28/08/2018 
¿Centros o cuerpos de delegados? Las luchas estudiantiles de los años setenta frente al debate acerca de las formas organizativas. El caso de la UBA 